\title{
Sylvie Chalaye
}

\section{Emanuela Cacchioli}

\section{(2) OpenEdition}

\section{Journals}

\section{Édition électronique}

URL : https://journals.openedition.org/studifrancesi/21784

DOI : 10.4000/studifrancesi.21784

ISSN : 2427-5856

\section{Éditeur}

Rosenberg \& Sellier

\section{Édition imprimée}

Date de publication : 1 décembre 2019

Pagination : 615-616

ISSN : 0039-2944

\section{Référence électronique}

Emanuela Cacchioli, «Sylvie Chalaye », Studi Francesi [En ligne], 189 (LXIII | III) | 2019, mis en ligne le

01 mars 2020, consulté le 11 novembre 2021. URL : http://journals.openedition.org/studifrancesi/ 21784 ; DOI : https://doi.org/10.4000/studifrancesi.21784

Ce document a été généré automatiquement le 11 novembre 2021.

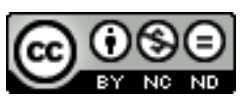

Studi Francesi è distribuita con Licenza Creative Commons Attribuzione - Non commerciale - Non opere derivate 4.0 Internazionale. 


\title{
Sylvie Chalaye
}

\author{
Emanuela Cacchioli
}

\section{RÉFÉRENCE}

Sylvie Chalaye, Corps marrons. Les poétiques de marronnage des dramaturgies afrocontemporaines, Caen, Éditions Passage(s), 2018, 138 pp.

1 Sylvie Chalaye consacre un petit volume très riche au théâtre afro-caribéen où elle nous propose une lecture centrée sur les poétiques du marronnage. Son intérêt pour les dramaturgies africaines et les travaux qu'elle y a consacrés sont déjà connus depuis longtemps grâce à ses essais, mais aussi au laboratoire SeFeA (Scènes francophones et écritures de l'altérité). Sa formation d'anthropologue lui a permis d'analyser les pièces africaines contemporaines à partir d'une perspective hybride. La chercheuse refuse de considérer l'ancrage de ce type de dramaturgies aux traditions gréco-latines et occidentales au profit de l'essence des pièces, des enjeux esthétiques, politiques, anthropologiques et philosophiques dérivant de la prise de conscience de l'altérité. Chalaye remarque que ces pièces sont hétérogènes si nous considérons le contexte de création, alors qu'elles ne cessent de mettre au centre de la scène l'altérité grâce au corps, en tant que théâtre du drame et réappropriation d'une identité niée. Pour sortir de toute interprétation occidentale, la chercheuse nous propose d'adopter les codes du marronnage, une pratique héritée de l'esclavage qui cherche à «trouver de l'espace là où on ne vous en laisse pas, à travailler dans le pli, à jouer des masques, à ne jamais être où on vous attend, et à inventer en ne comptant que sur soi» (p. 14). Le résultat de cette démarche est une dramaturgie qui déconcerte le spectateur et crée un effet de dépaysement. Le théâtre afro-caribéen nous propose aujourd'hui des formes de résistance et de subversion dérivant du marronnage qui se réalisent à travers le recours à l'oralité, au masque, au carnaval, au double jeu et à la lutte contre l'identité d'assignation.

2 Le volume de Sylvie Chalaye est assez court, mais dense et stratifié. Elle y aborde avant tout un bilan des dramaturgies afro-caribéennes en se focalisant sur les trente 
dernières années. On dirait qu'un nouveau modèle de théâtre s'est imposé: les écrivains ont cessé de questionner la recherche identitaire et ont choisi de s'ouvrir au monde afin de renouveler leur écriture et de trouver une forme d'émancipation qui aboutit à des pièces hybrides. À partir des années quatre-vingt-dix, les dramaturgies africaines et caribéennes se laissent traverser par toutes les influences possibles et acceptent de perdre une partie de leur identité afin de revendiquer leur entre-deux, leur positionnement au carrefour de cultures et de poétiques différentes. Grâce aux résidences d'écritures, aux festivals et à l'intérêt des médias, les écrivains afrocaribéens se rencontrent en France où ils font l'expérience de la diaspora et partagent une nouvelle esthétique qui se démarque de leurs origines. Ils choisissent la langue française, mais ils l'obligent à s'exprimer, à résonner différemment. Le passé ne peut pas être effacé car il habite ces dramaturges, mais il peut être reconstruit à partir d'une perspective différente. La mémoire agit sur l'individu, toutefois elle n'empêche pas de penser à l'avenir et de dépasser le vide que la dépossession de soi a généré après le déracinement et la traite esclavagiste. Chalaye retrace ensuite les origines du marronnage et leur valeur symbolique: l'esclave marron choisit de vivre dans les bois pour fuir l'espace aliénant de la plantation et reconquérir ses origines. Dans cette optique, le marronnage correspond à l'attitude créatrice envisagée par Glissant, c'est-àdire la création d'un espace d'invention en territoire dominé. Il faut, par conséquent, distinguer deux types de marronnage: le «grand» marronnage qui est puni par l'ordre colonial car l'esclave s'enfuit dans la forêt et le marronnage du quotidien qui met en place des stratégies de résistance permettant d'«avancer masqué» (p. 22). Ce dernier type de marronnage permet de s'emparer de sa dose de liberté sous la domination et, grâce à l'expression créative, de faire de la satire sous l'œil du maître qui ne la saisit pas.

3 Le corps devient donc porteur des traces de la traversée, du passé qui se manifeste par la danse, le chant, la musique. Si la critique a toujours considéré ces aspects comme des spécificités de l'esthétique africaine, les dramaturges revendiquent le «textocentrisme» (p. 29) et le corps devient l'espace de la représentation du tragique, l'outil du refus du conformisme physique et le centre d'une «poétique charnelle» (p.30) qui travaille l'écriture. La matérialité du corps se manifeste par les références au sang, aux excréments, à l'urine et à la sueur. Ce corps est aussi le théâtre du conflit car il est atteint dans son intégrité, il est sacrifié et il cache le mystère de la vie et de la mort. Il se fait mémoire et il est dépositaire des rituels initiatiques où les hommes défient la mort. Cependant, la dimension corporelle permet de retracer aussi la dispersion des origines, la diaspora et le théâtre devient le lieu de l'expression d'une histoire coloniale. Le retour du passé est toutefois possible grâce à la métamorphose du trépas qui se réalise avec la présence sur scène de spectres, de fantômes et de revenants. Normalement le corps renaît musicalement comme vibration, parole et la matière humaine passe de l'état solide à une consistance liquide ou volatile. Il en dérive donc que le corps et l'âme ne peuvent pas être séparés et si le corps réduit l'esclave à la condition d'objet et à la soumission au maître, l'esprit survit et trouve sa forme de revendication.

4 L'étude de Chalaye consacre trois chapitres aux spécificités de quelques écrivains qui traitent les aspects présentés. Il s'agit de Gerty Dambury, Kossi Efoui et Koffi Kwahulé. La dernière partie considère la présence animalière qui hante l'écriture: le spectateur a l'impression de voir sur scène un bestiaire étrange et inquiétant. Les animaux 
accompagnent les personnages, sont liés aux contes et aux proverbes et permettent de dire l'inarticulable.

5 Le corps parle même quand il est absent car le théâtre permet la récupération des rites funéraires et la création d'une communauté. La dramaturgie est donc un moyen de faire le deuil des origines et du déracinement. L'essai se conclut avec l'hypothèse d'une «cannibalisation théâtrale» car, selon Chalaye, la sépulture de son corps relève de l'anthropophagie. La digestion (de la nourriture et du corps) traduit la relation charnelle et permet de réfléchir sur la violence des relations humaines et sur la capacité de l'homme de se transformer pour «ingérer le monde» (p.121). Le cannibalisme est donc un témoignage de l'altérité et des enjeux migratoires.

Corps marrons aide le lecteur qui s'approche du théâtre afro-caribéen à saisir sa véritable dimension spécifique et à se détacher des paradigmes interprétatifs occidentaux. L'analyse est enrichie de nombreux exemples qui permettent de comprendre comment se réalisent les enjeux esthétiques, politiques et philosophiques. Des photos de l'actrice Bintou Dembélé sur scène accompagnent également la réflexion et complètent l'argumentation. 